\title{
Pesquisa participativa com mulheres assentadas: possibilidades a partir da educação popular em saúde
}

Iraí Maria de Campos Teixeira', Maria Waldenez Oliveira², Natália Sevilha Stofel ${ }^{3}$

\begin{abstract}
Resumo
Neste artigo apresentamos algumas reflexões teóricas e metodológicas oriundas de pesquisa participante com mulheres assentadas. Foram realizadas 24 idas a campo, dentre elas, 14 observações participantes, 9 entrevistas e uma roda de conversa. Nos primeiros encontros, conversamos sobre o andamento que daríamos à pesquisa anterior. Decidimos que a forma como planejam, se organizam, agem e se avaliam ao praticarem os cuidados à saúde seria um importante objeto desse estudo porque seus resultados possibilitam melhorar suas ações e também servirão de suporte para que outros grupos possam aprender com suas ações. Acreditamos na importância de aprendermos com as formas de ser, de saber e de fazer das mulheres camponesas, cujas práticas de cuidado à saúde contribuem para a superação das desigualdades e desafios que lhes são impostos, para manutenção de sua sobrevivência material e simbólica e para uma efetiva promoção da saúde da população do campo. Com esse trabalho, espera-se fortalecer as ações de cuidado à saúde realizadas por essas mulheres a partir de um processo dialógico de construção de pesquisa, que trará mais visibilidade às suas ações nos meios acadêmicos, políticos e sociais.
\end{abstract}

\section{Palavras-chave}

Mulheres. Educação e Saúde. Metodologia Científica.

1. Doutora em Educação pela Universidade Federal de São Carlos, São Paulo, Brasil. E-mail: iraimcteixeira@ gmail.com.

2. Doutora em Educação pela Universidade Federal de São Carlos, São Paulo, Brasil; professora titular na mesma instituição.E-mail: dmwo@ufscar.br.

3. Doutoranda em Enfermagem na Universidade Federal de Pelotas, Rio Grande do Sul, Brasil; professora na Universidade Federal do Pampa, Rio Grande do Sul, Brasil. E-mail: naty.stofel@gmail.com. 


\title{
Participatory research with women in settlements: possibilities from popular education in health
}

Iraí Maria de Campos Teixeira*, Maria Waldenez Oliveira**, Natália Sevilha Stofel ${ }^{* * *}$

\begin{abstract}
In this article we present some theoretical and methodological reflections from participant research with women in settlements. It carried out 24 field trips, among them, 14 participant observations, 9 interviews and a conversation circle. In the first meetings we talked about the progress we would make to the previous research. We decided that the way they plan, organize, act and evaluate themselves when practicing health care would be an important object of this study because their results can improve their actions and also support other groups in learning from their actions. We believe in the importance of learning from the ways of being, knowing and doing of peasant women whose health care practices contribute to overcoming the inequalities and challenges imposed on them, to maintain their material and symbolic survival, and to an effective health promotion of the rural population. With this work, it is hoped to strengthen the health care actions carried out by these women through a dialogical process of research construction, which will bring more visibility to their actions in academic, political and social environments.
\end{abstract}

\section{Keywords}

Women. Education and Health. Methodology.

* PhD in Education, Federal University of São Carlos, State of São Paulo, Brazil. E-mail: iraimcteixeira@gmail. com.

** PhD in Education, Federal University of São Carlos, State of São Paulo, Brazil; professor at the same institution. E-maildmwo@ufscar.br.

** PhD student in Nursing, Federal University of Pelotas, State of Rio Grande do Sul, Brazil; professor at the Federal University of Pampa, State of Rio Grande do Sil, Brazil. E-mail: naty.stofel@gmail.com. 


\section{Introdução}

A intenção deste artigo é apresentar algumas reflexões teórico-metodológicas acerca do processo de pesquisar em diálogo com grupos populares. Trata-se de uma sistematização da experiência de pesquisar junto a mulheres de um assentamento rural, localizado no interior de São Paulo, ao longo de todo o ano de 2013, com atualizações em janeiro de 2016, realizadas a partir de duas visitas feitas ao assentamento, nas quais se dialogou com cada participante com intuito de apresentar mais uma devolutiva do trabalho e atualizar as informações presentes nesse artigo.

Realizamos estudos e pesquisas com pessoas, grupos e comunidades muitas vezes marginalizados, desqualificados e excluídos pela sociedade. Nas palavras de Freire (2005, p. 103), "não se trata de ter nos homens e mulheres o objeto da investigação, de que o investigador seria o sujeito". Todos partilham, com papéis distintos, o protagonismo no desvelamento e na pronúncia do mundo.

Ao romper com a dualidade e o verticalismo que podem estar presentes na relação pesquisador-sujeito, reconhecemos que os participantes da pesquisa produzem cultura e conhecimento em suas relações com os outros no mundo. São esses sujeitos que podem nos ensinar sobre a experiência de marginalização, desqualificação e exclusão, assim como de lutas, conquistas e resistências.

Parte da premissa da educação popular e saúde, naqual estetrabalhoseinsere, fundamentase na relação de interação e confiança que se busca estabelecer entre pesquisador da academia e sujeitos com quem se pesquisa. Busca-se que essa relação não seja marcada por hierarquias ou imposições que caracterizam uma relação de poder, a qual é facilmente percebida quando se tratam pessoas, grupos e comunidades como simples objetos de pesquisa.

Para tanto, o/a pesquisador/a deve realizar uma cuidadosa e paciente inserção na comunidade, instituição ou espaço social onde se quer pesquisar, para conviver com os sujeitos. É necessário se dispor a acolher e também a ser acolhido por esse grupo. Conviver com a intenção de conhecer, compreender e não julgar. Essa inserção é insuficiente se ficar apenas no olhar, se não participar da dinâmica, das tarefas, do cotidiano dessa comunidade (OLIVEIRA et al., 2014). É possível que nesse processo de inserção haja um desconforto, um incômodo entre as pessoas que se relacionam. Por isso a disposição de acolher e de ser acolhido é tão importante. Para superar o incômodo, é importante se esforçar para fazer parte, se oferecer para ser útil, ajudar e contribuir. Esse processo exige tempo e paciência e não se constrói uma relação de confiança em uma visita. São necessários vários encontros para que se estabeleça essa relação. Não há regra ou cronograma pré-estabelecido para o tempo de inserção. É preciso conviver e dialogar com os sujeitos para perceber os vínculos que estão sendo construídos (OLIVEIRA et al., 2014).

Uma postura que propicie o diálogo pressupõe a compreensão de que saberes são referenciados em percepções da realidade, visões de mundo e vivências. População e profissionais técnicos constroem saberes diferentes, pois suas referências são distintas, contudo, seus saberes não devem ser diferenciados enquanto superiores ou inferiores (OLIVEIRA et al., 2014).

A diversidade que se apresenta no encontro entre grupos populares e acadêmicos enriquece a construção de novos saberes. Por isso acreditamos na importância do diálogo ao pesquisarmos com grupos populares. Reconhecemos que os saberes construídos nesse encontro são o caminho e a chave para uma transformação social no sentido de pronunciar e transformar o mundo percebido. 
Conhecer a experiência vivida de outros só é possível se houver estranhamento respeitoso à cultura do outro, aos seus pontos de vista (OLIVEIRA et al., 2014). Na construção de saberes entre diferentes visões de mundo, divergências são esperadas, contudo, o diálogo, que pressupões respeito e amorosidade, é fundamental para que a comunicação entre os sujeitos prevaleça. "Se não amo o mundo, se não amo a vida, se não amo os seres humanos, não me é possível o diálogo" (FREIRE, 2005, p. 92).

A convivência dialógica se nutre na simpatia, na confiança, na humildade, na sensibilidade, no respeito (OLIVEIRA; STOTZ, 2004). Se funda no amor e na fé no ser humano que se permite estar e aprender com o outro (FREIRE, 2005). Não é necessário concordar para se ser dialógico, as opiniões sobre um determinado tema podem divergir, como já foi dito, mas quando o diálogo é estabelecido há escuta, cuidado e reflexão. A convivência não dialógica não agrega no processo de libertação e transformação.

$\mathrm{Na}$ convivência promove-se a conscientização, aprendizado autêntico pelo qual, segundo Freire (2005), se constrói a autonomia dos sujeitos. "Mas ninguém se conscientiza separadamente dos demais. A consciência se constitui como consciência do mundo" (FIORI, 1986, p. 9). A consciência do mundo e a consciência de si crescem juntas. Por meio do diálogo, os sujeitos que convivem, compartilham seu aprendizado autêntico, sua consciência de mundo.

Essa pesquisa fundamenta-se na convivência dialógica por favorecer o processo de libertação e humanização dos sujeitos envolvidos, tanto colaboradores/as quanto pesquisadores/as. Destacamos que a convivência aqui estabelecida não se configura como etapa ou procedimento de pesquisa, ela é o próprio processo de pesquisar.

\section{Pesquisa Participante}

Inserir-se, estabelecer relações de interação e confiança, estar disposta a acolher e ser acolhida faz parte da postura ético-política adotada e conduz às escolhas metodológicas. Entendemos ser responsabilidade da pesquisadora a tomada de decisão perante a comunidade acadêmica, contudo, os percursos que se constroem na pesquisa são decorrentes dos diálogos e reflexões gerados na convivência em que se articulam as experiências vividas com os sujeitos de pesquisa e também com outros pesquisadores ou estudiosos (ARAÚJO-OLIVEIRA, 2014).

Faz parte de nossa atuação política conduzir a pesquisa com o intuito de, junto aos sujeitos envolvidos, transformar a realidade que se quer transformada. Assim como afirma Oliveira e Moraes (2010, p. 310), "no trabalho conjunto buscamos viver e construir, cotidianamente, ações dialógicas no enfrentamento das desigualdades sociais e na recriação humanizadora do mundo". Métodos participativos de pesquisa, como é o caso da Pesquisa Participante, se caracterizam pelo compromisso do/a pesquisador/a, com a realidade social, orientado a favorecer a participação de todas as pessoas na transformação e melhoria de seu meio social (VÁZQUEZ NAVARRETE et al., 2009).

$\mathrm{Na}$ Pesquisa Participante a investigação em comunidades populares é uma atividade política e pedagógica mais ampla e de maior continuidade que a pesquisa. Desta forma, a pesquisadora constrói o projeto científico de pesquisa dialogando com o projeto político dos grupos populares cuja situação de classe, cultura ou história se quer conhecer porque nele se quer agir (BRANDÃO, 1981). Ezpeletta e Rocwell (1989) ressaltam ainda que, para que a construção do projeto de 
pesquisa possa ser conjunta, o vínculo entre pesquisador e sujeitos deve ser estreitado.

Segundo Ribeiro Junior (2009, p. 58), nesse tipo de metodologia "os pesquisadores ou pesquisadoras trazem para seus trabalhos científicos experiências de vida que condicionam uma visão de mundo". Tal visão de mundo marca a "intencionalidade de seus atos, a natureza e a finalidade de sua pesquisa e a escolha dos instrumentos metodológicos a serem utilizados" (OLIVEIRA; OLIVEIRA, 1981, p. 24).

Gajardo (1987) apresenta quatro grandes eixos da pesquisa participante nos quais se fundem as ações investigativa, educativa e política: (1) rompimento do monopólio do saber e da informação pelos intelectuais e pesquisadores por meio da produção coletiva dos conhecimentos e da apropriação destes pelos grupos marginalizados em suas lutas; (2) análise coletiva da informação e da forma de usá-la; (3) análise crítica dos dados, buscando as causas dos problemas e as alternativas de solução e (4) a compreensão da relação entre problemas individuais e coletivos, funcionais e estruturais.

Demo (1987, p. 125) apresenta cinco passos para definir a Pesquisa Participante: "1. formulação da problemática provisória (conceitos, objetivos, hipótese); 2. escolha de variáveis a observar e dos instrumentos de pesquisa; 3. observação das variáveis; 4 . análise e síntese dos dados; 5. elaboração de uma nova problemática". Concomitante a estes passos, é previsto o retorno constante da pesquisa à população envolvida, denominado pelo autor como retroalimentação.

Como Le Boterf (1987, p. 52) afirma, "não existe um modelo único de pesquisa participante, pois se trata, na verdade, de adaptar em cada caso o processo às condições particulares de cada situação concreta (os recursos, as limitações, o contexto sociopolítico, os objetivos propostos etc.)".

Ao refletir sobre metodologias de pesquisa em espaços sociais, Oliveira et al.
(2014) orientam sobre a importância de que os objetivos e a questão de pesquisa sejam pensados e repensados junto com as participantes da pesquisa, assim como os resultados do trabalho sejam retornados à comunidade.

Considerando a particularidade de cada pesquisa, apresentamos a nossa proposta de Pesquisa Participante composta por quatro etapas que se aproximam das proposições teórico-metodológicas da educação popular e saúde nas quais se inspirou a pesquisa:

Primeira etapa - construção do projeto de pesquisa junto à população: tendo realizado a inserção e o estreitamento dos vínculos, essa etapa consiste em definir questões, objetivos e métodos junto com as participantes da pesquisa. Pensar o projeto de pesquisa com a população: foi apresentada a proposta de se realizar uma Pesquisa Participante para as mulheres do assentamento, convidandoas a participarem ativamente da pesquisa e a formularem, reformularem e validarem questões e objetivos de acordo com o interesse delas.

Segunda etapa - estudo da região junto à população envolvida: na convivência e no diálogo, foram realizadas as observações de natureza participante da realidade cotidiana da vida das camponesas. A observação participante é aquela na qual o pesquisador se integra à realidade que pretende observar, convertendose em um a mais do grupo social objeto de estudo. Nela se favorece a intersubjetividade, incluindo ao investigador. Busca descobrir o sentido, a dinâmica e os processos dos acontecimentos que se dão em um determinado contexto social desde o ponto de vista dos participantes (VÁZQUEZ NAVARRETE et al., 2009, p. 69).

Nessa etapa, conhece-se o ponto de vista das pessoas e dos grupos envolvidos e uma análise preliminar e provisória desses dados é realizada.

Terceira etapa - análise crítica dos problemas: a partir da primeira análise crítica dos problemas investigados, se formulam novas questões que auxiliarão na elaboração de um 
roteiro de entrevistas, quando os dados serão aprofundados. Nesta etapa a questão que se investiga é aprofundada por meio de entrevistas semiestruturadas individuais e/ou coletivas.

Quarta etapa - discussão dos resultados junto à população: consistiu na corroboração, junto com as mulheres participantes da pesquisa, dos dados obtidos e análises realizadas. Esta etapa também prevê a sistematização e divulgação da experiência junto com as participantes por meio de publicações e participação em eventos. Para tanto, realizou-se uma roda de conversa.

\section{Procedimentos metodológicos}

Na coleta de dados, foram feitos registros em diário de campo das observações participantes e foram realizadas entrevistas individuais e coletivas. Antes de sair a campo para realizar as observações participantes, Larrosa-Bondía (2002) orienta a registrarmos em diário de campo pré-anotações baseadas nesse estudo preliminar que serão usadas em contraposição aos dados encontrados nos espaços sociais onde vamos pesquisar. A partir dessas pré-anotações foi elaborado um Roteiro de Observações para auxiliar a coleta de dados.

As observações participantes são registradas em diário de campo. Na elaboração de um diário de campo se descrevem "as reflexões pessoais assim como as vivências, as percepções, as expectativas, as relações estabelecidas com os sujeitos, seus sentimentos, suas expressões" (VÁZQUEZ NAVARRETE et al., 2009, p. 70).

Para auxiliar nesses registros e na posterior análise dos dados, recorreu-se a gravações de áudio e registros fotográficos previamente autorizados pelas participantes da pesquisa.

Para que a memória das observações participantes não se perdesse até a ocasião dos registros em diário de campo, durante o trajeto de volta das coletas realizavam-se registros em arquivos de voz contendo descrições das observações, relatos pessoais da experiência e reflexões provenientes da convivência. Além disso, também durante as observações participantes, alguns momentos de conversas foram gravados em áudio para que os detalhes não se perdessem, sendo posteriormente transcritas em diário de campo. As falas transcritas a partir das gravações de áudio, realizadas durante as observações participantes, serão apresentadas na íntegra, constando o nome da participante e número do diário de campo no qual se encontra o registro.

Os dados coletados por meio das observações participantes e registro em diário de campo foram analisados e as entrevistas semiestruturadas realizadas a fim de aprofundarmos as questões levantadas a partir da primeira análise.

A entrevista semiestruturada, para Manzini (2012, p. 156)

tem como característica um roteiro com perguntas abertas e é indicada para estudar um fenômeno com uma população específica: grupo de professores; grupo de alunos; grupo de enfermeiras, etc. Deve existir flexibilidade na sequência da apresentação das perguntas ao entrevistado e o entrevistador pode realizar perguntas complementares para entender melhor o fenômeno em pauta.

Segundo Queiroz (1987), trata-se de definir núcleos de interesse que têm vinculação direta aos seus pressupostos teóricos da pesquisa (abordagem conceitual) e contatos prévios com a realidade em estudo; ou seja, existe uma direção para o conteúdo que vai ser obtido nas entrevistas ao mesmo tempo em que há a garantia de adequação do roteiro conforme acontecem as entrevistas.

De acordo com Alves e Silva (1992, p. 64), esse formato pede "uma formulação flexível das questões, cuja sequência e minuciosidade ficarão por conta do discurso dos sujeitos e da dinâmica que flui naturalmente no momento em que entrevistador e 
entrevistado se defrontam e partilham uma conversa permeada de perguntas abertas". Segundo as autoras, esse tipo de entrevista permite investigar crenças, sentimentos, valores, razões e motivos que se fazem acompanhar de fatos e comportamentos, numa captação na íntegra da fala dos sujeitos.

\section{Procedimentos de análise dos dados e apresentação dos resultados}

Os dados coletados foram analisados segundo a Análise de Conteúdo, que visa estabelecer categorias de análise. Para elaboração das categorias foi feita uma leitura inicial da transcrição das entrevistas, bem como do que foi registrado em diário de campo buscando apreender um sentido na totalidade dos dados obtidos (BARDIN, 2008).

A pré-análise dos dados constitui a etapa de organização do material coletado. Nessa etapa, chamada de "leitura flutuante", formulamos hipóteses amplas e provisórias sobre como tratar os dados (BARDIN, 2008).

Após leitura inicial foi feita uma releitura criteriosa de todo material coletado visando estabelecer áreas temáticas e detectar categorias de análise, sempre focalizando o objeto de estudo (BARDIN, 2008).

A última fase se constituiu do tratamento dos dados obtidos e sua interpretação. Finalmente, procuramos expressar os significados contidos nas categorias identificadas, buscando responder ao questionamento da pesquisa. Esse material foi organizado em uma síntese que apresenta a descrição do objeto de estudo. Não se trata de apresentar a interpretação pessoal da pesquisadora, mas sim de elucidar a trajetória traçada no sentido de compreender o objeto investigado à luz de relatos e interpretações fornecidos pelas próprias mulheres (MINAYO, 2004).

\section{Reflexões compartilhadas e validação dos resultados junto à população}

Para conhecer o cotidiano por meio de observações de natureza participante, houve uma ativa participação nas atividades de produção de doces e pães na panificadora, nas reuniões do grupo de mulheres, nas vendas em feiras e eventos, além de almoços com as famílias e visitas aos sítios, para participar do cotidiano de trabalho na lida do campo.

Após realizar as observações participantes e as entrevistas individuas e coletivas empreendeu-se uma roda de conversa a fim de refletirmos em grupo sobre os dados apreendidos na análise de conteúdo sob a forma de categorias.

A roda de conversa é, no âmbito da pesquisa qualitativa, uma forma de produzir dados em que o pesquisador se insere na conversa e, ao mesmo tempo, produz dados para discussão. É, na verdade, um instrumento que permite a partilha de experiências e o desenvolvimento de reflexões sobre os processos educativos dos sujeitos, em um processo mediado pela interação com os pares, através de diálogos internos e no silêncio observador e reflexivo (MOURA; LIMA, 2014, p. 99).

A roda de conversa, metodologia bastante utilizada nos processos de leitura e intervenção comunitária, consiste em um método de participação coletiva de debates acerca de uma temática, através da criação de espaços de diálogo nos quais os sujeitos podem se expressar e, sobretudo, escutar os outros e a si mesmos. Tem como principal objetivo motivar a construção da autonomia dos sujeitos por meio da problematização, da socialização de saberes e da reflexão voltada para a ação. Envolve, portanto, um conjunto de trocas de experiências, conversas, discussão e divulgação de conhecimentos entre os envolvidos nesta metodologia (NASCIMENTO; SILVA, 2009).

De acordo com Méllo et al. (2007), a roda 
de conversa prioriza discussões em torno de uma temática (selecionada de acordo com os objetivos da pesquisa) e, no processo dialógico, as pessoas podem apresentar suas elaborações, mesmo contraditórias, sendo que cada pessoa instiga a outra a falar, sendo possível se posicionar e ouvir o posicionamento do outro. Nessas discussões, ao mesmo tempo em que as pessoas falam suas histórias buscam compreendê-las por meio do exercício de pensar compartilhado, o qual possibilita a significação dos acontecimentos.

Afonso e Abade (2008) destacam que a roda de conversa é utilizada nas metodologias participativas. Seu referencial teórico parte da articulação de autores da psicologia social, da psicanálise, da educação e seu fundamento metodológico se alicerça nas oficinas de intervenção psicossocial, tendo por objetivo a constituição de um espaço no qual seus participantes reflitam acerca do cotidiano, ou seja, de sua relação com o mundo, com o trabalho, com o projeto de vida.

Para que isso ocorra, a roda deve ser desenvolvida em um contexto onde as pessoas possam se expressar, buscando superar seus próprios medos e entraves. Para auxiliá-las nesse processo de quebra dos entraves, bem como para facilitar a comunicação e a interação, se pode fazer uso de técnicas de dinamização de grupo, sendo utilizados recursos lúdicos ou não. Apesar de os coordenadores poderem escolher uma técnica visando um objetivo, é o grupo quem "dá a palavra final", ou seja, é ele quem vivencia e direciona a técnica para seus objetivos (AFONSO; ABADE, 2008).

Deacordocom Moura eLima (2014, p. 98):

A conversa é um espaço de formação, de troca de experiências, de confraternização, de desabafo, muda caminhos, forja opiniões, razão por que a Roda de Conversa surge como uma forma de reviver o prazer da troca e de produzir dados ricos em conteúdo e significado para a pesquisa na área de educação. No contexto da Roda de Conversa, o diálogo é um momento singular de partilha, uma vez que pressupõe um exercício de escuta e fala. As colocações de cada participante são construídas a partir da interação com o outro, sejam para complementar, discordar, sejam para concordar com a fala imediatamente anterior. Conversar, nessa acepção, remete à compreensão de mais profundidade, de mais reflexão, assim como de ponderação, no sentido de melhor percepção, de franco compartilhamento.

A utilização da metodologia de roda de conversa favorece a construção de uma prática dialógica em pesquisa, que possibilita o exercício de pensar compartilhado (FIGUEIREDO; QUEIROZ, 2013). Essa metodologia se faz participativa, pois quanto mais as participantes assumem uma postura ativa na investigação de sua temática, tanto mais aprofundam sua tomada de consciência em torno da realidade e, explicitando sua temática significativa, se apropriam dela.

\section{Caminhar metodológico}

Anterior à aprovação no processo seletivo para o doutorado, reuni-me com as mulheres participantes da pesquisa de mestrado para discutirmos sobre uma proposta para o doutorado. Assim, começamos a nos aproximar do grupo participante e iniciamos a primeira etapa da pesquisa participante.

Nesse trabalho, o compromisso ético e social foi ponto de partida e ponto de chegada. Após o projeto ser aprovado pelo Comitê de Ética ${ }^{4}$ foram realizados encontros com o grupo de mulheres que manifestaram querer participar. Objetivos e questão de pesquisa foram reelaborados e corroborados

4. Esta pesquisa foi realizada de acordo com a Resolução 196/96 e aprovada pelo Comitê de Ética e Pesquisa com Seres Humanos, parecer número 234.940. Todos/as que participaram da pesquisa assinaram o Termo de Consentimento Livre e Esclarecido aprovado pelo Comitê de Ética 
pela pesquisadora e pelo grupo, como já antecipado na primeira etapa da pesquisa.

Para compor o grupo de participantes, foram convidadas todas as mulheres da Associação de Mulheres do Assentamento. A partir desse convite, outras mulheres tiveram interesse em participar da pesquisa totalizando onze mulheres. Das onze participantes, cinco compunham a Associação de Mulheres do Assentamento, quatro eram Agentes Comunitárias de Saúde - ACS da Equipe de Saúde da Família do assentamento; uma era participante da associação e também agente comunitária de saúde no assentamento; e uma era feirante e trabalhou como auxiliar de limpeza da Unidade de Saúde no período de coleta de dados, quando foi convidada a participar da pesquisa. Todas eram assentadas e trabalham nos sítios, se dedicando ao roçado e à criação de animais, além dos cuidados domésticos como limpeza da casa e preparo de alimentos.

No Quadro 1, segue uma breve apresentação de cada mulher ${ }^{5}$ na tentativa de conhecermos um pouco quem está construindo esse conhecimento acerca do cuidado à saúde de mulheres camponesas e suas trajetórias pessoais.

Quadro 1 - Apresentação das participantes da pesquisa por ordem alfabética.

ELIZETE (ZETE) tem 48 anos, nasceu no estado de São Paulo, mas cresceu no Paraná. Trabalhou na panificadora e é associada. Possui ensino fundamental incompleto. É casada, tem dois filhos e uma filha que vivem com ela.

FERNANDA tem 32 anos, nasceu em Matão - interior de São Paulo, é formada em Administração, trabalha na panificadora e é associada. É nora de Sueli e moram no mesmo lote com seu marido e filha recémnascida.

FLÁVIA tem 37anos, nasceu em Araraquara - SP. É Agente comunitária de Saúde. Possui ensino médio completo. É casada e tem dois filhos. Moram no sítio com a mãe dela, o padrasto, as irmãs e uma sobrinha, enquanto está construindo no lote que adquiriu no assentamento.

JISELI tem 51 anos, nasceu e cresceu no interior da Bahia, é associada, trabalha na panificadora e é feirante. Fez supletivo para completar o ensino médio. É casada, tem duas filhas, um filho, quatro netas e um neto que moram na cidade. Vive com o marido no sítio.

LEONILDA tem 38 anos, nasceu em Santana do Itararé - Paraná. É Agente comunitária de Saúde e faz parte da associação de moradores. Possui ensino médio completo. É casada, tem três filhos (6, 11 e 19 anos) que vivem com ela e o marido no sítio. Seu pai e sua mãe também moram com eles.

MARIA JOSÉ tem 57 anos, nasceu em São João Evangelista - MG. Viveu em Campo Morão - Paraná, onde casou e de onde veio para o assentamento. Trabalha na panificadora e é associada. Possui ensino fundamental incompleto. Casou com 18 anos e após um ano e meio ficou viúva. Nessa época tinha dois filhos. Aos 22 anos casou-se novamente e teve mais seis filhos. Seu marido já tinha cinco filhos, de modo que criou 13 filhos. Ficou viúva novamente e atualmente está casada com o companheiro com quem vive no sítio, e mais três netos.

MARLI tem 47 anos, nasceu no ABC Paulista. É agente comunitária de saúde. Possui ensino médio completo. É casada e tem três filhos (17, 19 e 24 anos) que vivem com ela.

5. Dados atualizados em janeiro de 2016. Escolhemos como informações relevantes para apresentar cada participante: o nome, a idade, a escolaridade, a naturalidade, estado civil, filhos e com quem moram. Mantivemos os nomes reais das participantes ao longo do trabalho, pois é de interesse delas serem reconhecidas enquanto sujeitos das ações que são descritas. 
PRETA tem 49 anos, nasceu em Riolândia - interior de São Paulo. É Agente comunitária de Saúde e é associada. Possui ensino médio completo. É casada e não tem filhos. Vive com o marido no sítio.

SUELI tem 59 anos, nasceu em Pitanga, Paraná, trabalha na panificadora e é associada. Possui ensino fundamental completo. É divorciada, tem dois filhos e uma filha. Um dos filhos vive no mesmo lote com a esposa, Fernanda e a filha (neta de Sueli). Mãe de Sueli também mora nesse lote. São três casas no lote e as famílias dividem as tarefas de cuidado com o sítio.

VÂNIA tem 27 anos, nasceu em Araraquara, interior de São Paulo. É agricultora e feirante. Não é associada. Possui ensino fundamental completo. Trabalhou como Auxiliar de limpeza da Unidade de Saúde no período de coleta de dados e participa das reuniões da associação.

WANDA tem 38 anos, nasceu em Boa Esperança do Sul, interior de São Paulo. É Agente comunitária de Saúde. Possui ensino médio completo. É casada e vive com o marido no sítio.

Fonte: Os autores (2018).

Nos primeiros encontros, conversamos sobre o andamento que daríamos à pesquisa anterior, que investigou os processos educativos decorrentes dos cuidados à saúde praticados por elas. Decidimos que a forma como planejam, se organizam, agem e se avaliam ao praticarem os cuidados à saúde seria um importante objeto desse estudo porque seus resultados possibilitam melhorar suas ações e também servirão de suporte para que outros grupos possam aprender com suas ações. Após definir a questão de pesquisa iniciamos a segunda etapa, que foi conhecer o cotidiano por meio de observações de natureza participante. Nesse processo uma das autoras desse artigo participava das atividades de produção de doces e pães na panificadora; de reuniões do grupo de mulheres; de vendas nas feiras; da organização de eventos; além de participar do cotidiano nos sítios, de cafés e almoços com as famílias para os quais foi convidada. Ao longo da coleta de dados discutimos sobre as ações cotidianas de cuidado à saúde e buscou-se compreender os processos educativos envolvidos nessas ações.

Para ampliar as percepções sobre a vida no assentamento e para conhecer outras perspectivas sobre a temática de pesquisa, também se realizou visitas à escola, à unidade de saúde, à Fundação Instituto de Terras do Estado de São Paulo (ITESP), à Federação dos Empregados Assalariados Rurais do Estado de São Paulo (FERAESP) e à sede do Instituto Nacional Colonização e Reforma Agrária - Instituto Biosistêmico (INCRA/IBS) em Araraquara, quando se conversou com sujeitos que chamamos aqui de colaboradoras e colaboradores da pesquisa ${ }^{6}$.

No período de observações, foi acompanhado o cotidiano das participantes e buscou-se vivenciar com elas e outros colaboradores e colaboradoras o cotidiano no assentamento. Eles/elas foram indicados/as pelas participantes da pesquisa. As participantes, ao

6. Participantes da pesquisa são as mulheres que participam dessa pesquisa como sujeitos e pesquisadoras, tendo sugerido que esta pesquisa acontecesse e/ou tendo participado das etapas de definição de tema, objetivos, seleção de sujeitos colaboradores/as, entrevistas e validação dos dados analisados. Por outro lado, colaboradores e colaboradoras da pesquisa são as pessoas indicadas pelas participantes para contribuírem sobre a temática central desse trabalho. Com esses sujeitos conversamos sobre o cuidado à saúde e seus processos educativos, sobre o histórico do assentamento, também levantamos percepções sobre a realidade vivida no Assentamento. Esses sujeitos contribuíram para a pesquisa com suas histórias de vida, suas perspectivas sobre o tema, apontando conflitos, tensões, soluções e superações. 
longo da convivência metodológica, definiram com a pesquisadora quem eram as pessoas com quem precisávamos conversar para contribuírem com a nossa investigação.

Definimos esses sujeitos seguindo os seguintes critérios: 1) Sujeitos inseridos no fenômeno que estamos investigando (ações de cuidado à saúde promovidas por mulheres camponesas); 2) Sujeitos com experiências para contribuirnainvestigaçãodetemasespecíficos, tais como: uso de ervas, descrição do assentamento, educação de crianças e adolescentes. Articulamos com essas pessoas datas e locais para que pudéssemos nos encontrar e realizar as entrevistas individuais e coletivas. Percebemos o protagonismo e autonomia dessas mulheres enquanto investigadoras nesse processo da pesquisa. Nos momentos dos encontros com esses sujeitos, elas acompanhavam a pesquisadora até o local combinado; em algumas conversas, participavam fazendo perguntas, ajudando a aprofundar o tema.

Alguns/alguma desses/as colaboradores/ as quiseram participar da pesquisa, mas não quiseram ter seus nomes reais divulgados (Quadro 2). Dessa forma, usaremos nomes fictícios para nos referenciarmos a eles/elas.

Quadro 2 - Colaboradores e colaboradoras da pesquisa.

\begin{tabular}{|l|l|}
\hline Relação de colaboradores & Nome fictício \\
\hline Colaboradora 1 & Girassol \\
\hline Colaborador 2 & Cravo \\
\hline Colaboradora 3 & Azaleia \\
\hline Colaborador 4 & Crisântemo \\
\hline Colaborador 5 & Líro \\
\hline Colaboradora 6 & Rosa \\
\hline Colaboradora 7 & Tulipa \\
\hline
\end{tabular}

Fonte: As autoras (2018).

Conforme previsto na terceira etapa da foram analisados e, posteriormente, foram pesquisa participante proposta aqui, os realizadas nove entrevistas semiestruturadas dados coletados por meio das observações para o aprofundamento das questões levantadas participantes e registro em diário de campo a partir dessa primeira análise. 
Quadro 3 - Descrição das participações em cada entrevista semiestruturada realizada

\begin{tabular}{|l|l|}
\hline Relação de entrevistas & Participante(s) \\
\hline Entrevista 1 & Girassol e Cravo \\
\hline Entrevista 2 & Azaleia \\
\hline Entrevista 3 & Flávia \\
\hline Entrevista 4 & Leonilda \\
\hline Entrevista 5 & Crisântemo \\
\hline Entrevista 6 & Lírio \\
\hline Entrevista 7 & Rosa e Tulipa \\
\hline Entrevista 8 & Maria \\
\hline Entrevista 9 & Sueli e Jiseli \\
\hline
\end{tabular}

Fonte: As autoras (2018).

O levantamento dos temas das entrevistas foi resultado da busca por unidades significativas com o objetivo de aprofundar nossa compreensão sobre os primeiros dados coletados. Tais temas isolados não expressam a totalidade da realidade vivenciada pelas mulheres no cuidado à saúde, contudo, a reflexão a respeito desses temas e o esforço em identificar a relação entre eles torna possível nossa compreensão mais ampliada dessa realidade.

Tendo como foco do estudo os processos educativos decorrentes da prática do cuidado à saúde, destacaram-se os seguintes temas para serem aprofundados: 1) Projetos de saúde; 2) Relações familiares; 3) Conflitos e tensões na promoção do cuidado à saúde e 4) Práticas populares de saúde.

Após concluir a coleta de dados, iniciamos a quarta etapa da pesquisa, que prevê que os dados sejam analisados, discutidos e corroborados com a população. Procurando trabalhar com a reflexão e o diálogo, utilizamos a metodologia da roda de conversa nessa etapa da pesquisa. Participantes da pesquisa, colaboradores/as e demais mulheres do assentamento foram convidadas. Estiveram presentes na roda vinte mulheres, dentre elas, seis participantes e três colaboradoras.

$\mathrm{Na}$ roda de conversa, descrevemos para as demais mulheres nosso processo de pesquisar, relatando as etapas vivenciadas e como chegamos à questão de pesquisa, que foi apresentada para o grupo e discutida a partir das categorias previamente apreendidas.

Ao organizarmos a roda de conversa, as participantes sugeriram, como forma de divulgação do trabalho e validação dos dados por parte da população de mulheres do assentamento, convidarmos as colaboradoras e outras mulheres que atendessem aos prérequisitos utilizados na seleção de colaboradoras e colaboradores. Disseram que, pelo teor do trabalho tratar-se de processos educativos em saúde de mulheres do assentamento, os resultados deveriam ter a aprovação do maior número possível de mulheres do assentamento. Como dinâmica para a roda, planejamos a realização de um café da manhã solidário e, por iniciativa das participantes da pesquisa, as pessoas convidadas a participarem da roda foram 
convidadas a participar de umavivência de dança.

Talvivênciafoisolicitada pelas participantes com o intuito de descontrair e para identificar as mulheres que têm interesse na prática para, em uma ação futura, desenvolverem um trabalho de cuidado à saúde com danças no assentamento. Em diálogo, para organizarmos a roda de conversa, elas expressaram:

Sabe o que precisava ter? Uma dança! A gente chama as meninas para dançarem e quem levantar a gente observa. E fica de olho nela. É um jeito da gente prestar mais atenção em quem está precisando dançar. [...] Porque essa ação melhora a autoestima das mulheres. Elas precisam se movimentar, se mexerem um pouco. Se sentirem bonitas. Se sentirem bem. (PRETA - Diário de campo XIV).

\section{Análise dos dados}

Os dados coletados demonstraram que as participantes da pesquisa têm em comum um projeto de saúde, de vida de qualidade, que as aproxima e direciona suas ações de cuidado. Nesse processo de busca comum por saúde para a comunidade, elas aprenderam a estabelecer relações dialógicas, a ser solidárias entre si, a se organizar, a dividir tarefas, a expor os resultados de suas ações a fim de atrair maior participação em ações futuras.

Muitos de seus processos educativos acerca do cuidado à saúde ocorrem nas relações intergeracionais, nas relações familiares e nas relações étnico-raciais. A diversidade presente nessas relações educa para o cuidado, pois agrega novas e diferentes perspectivas sobre a vida no campo; uso de tecnologias; cuidados com a terra e com todos os seres terrenos; luta por direitos; autoimagem, autocuidado, autorrealização e autoestima; participação popular; solidariedade; afeto; humildade e admiração.

É preciso reconhecer, respeitar e valorizar as diferentes raízes históricas e culturais do campo e da floresta. A sabedoria ancestral dos oprimidos pela lógica da colonialidade deve auxiliar no processo de se pensar o cuidado à saúde nas estratégias políticas. Esses saberes contribuem nos âmbitos da formação e da prática profissional, que se quer centrada no diálogo, na autonomia e na liberdade.

Os dados demonstraram que a luta pela terra é a luta pela vida, por melhores condições de alimentação, habitação, trabalho, lazer, educação e produção. Tudo isso é luta por saúde, na concepção das mulheres do Assentamento Monte Alegre e dos movimentos de luta pela terra, as quais percebem nas conquistas dos/as camponeses/as o renascimento da vida humana e da natureza.

Assim como a luta pela terra, o trabalho e a geração de renda se mostraram como importantes dimensões do cuidado à saúde. Os dados coletados demonstraram mudanças no cotidiano das mulheres camponesas que, ao buscarem novas formas de gerar renda, formando associações, se capacitando constantemente, conquistam espaços de sociabilidade. Além da geração de renda, o trabalho fora do lar, os cursos, palestras e viagens, possibilitam o reconhecimento das associadas por parte da sociedade.

Essas mulheres atuam na construção de espaços de sociabilidade. $\mathrm{O}$ ato de cozinhar e produzir pães e massas passou a ter sentido público, sendo reconhecido como trabalho efetivo na geração de renda. Por meio dessa iniciativa, percebemos a possibilidade de se promover um sentido diferenciado do trabalho da camponesa para além do âmbito familiar e dos afazeres domésticos. Elas deixaram de ter vergonha de si e fazem de sua identidade camponesa um forte elemento na divulgação de seus produtos naturais, caseiros, orgânicos que, ao invés de desvalorizarem a mercadoria, agregam valor ao produto final, devido a crescente procura por produtos livres de resíduos tóxicos ou transgênicos. Podemos afirmar que a inserção das 
mulheres camponesas em espaços de ampla sociabilidade tem possibilitado um aprendizado que também se dá em esferas organizativa e produtiva. Esse grupo de mulheres tem como perspectivas possibilitar às demais camponesas a incorporação de um saber/ poder que deve refletir no processo de decisão das ações que beneficiem os assentamentos.

A luta por ampliar a participação popular resultou na abertura do poder público municipal à transformação possível dos papéis das mulheres assentadas. A construção de uma identidade política e mediada pelos novos horizontes que se abrem nas políticas públicas para o campo não implica necessariamente em rompimento com as formas de dominação anteriormente vigentes. Novos lugares foram constituídos pelos movimentos sociais, pelos formuladores das práticas públicas. Aqueles não trazem, como consequência, uma (re) socialização que inverta posições naturalizadas e, de fato, levem a mulher a entrar no campo dos direitos em todas as dimensões da vida social.

Assim, todo o processo de pesquisa percorrido, quando refletido acerca de cada encontro, cada detalhe elaborado por todas as envolvidas na pesquisa, vai ao encontro com o conceito de empoderamento colocado por Stoltz (2009), pois as mulheres do assentamento empode(ra)ram-se para tomar decisões e estabelecer prioridades, buscando parceria na resolução de problemas, na perspectiva que seus avanços ocorram articuladamente às possibilidades de transformações gerais da sociedade, rumo a um projeto de emancipação de todos.

Entretanto, pode-se afirmar que o papel das mulheres participantes dessa pesquisa e que ocupam outros espaços que não aqueles da esfera doméstica tem superado em parte aqueles que se consolidaram historicamente. As políticas públicas, por vezes, não focam o segmento feminino, contudo, as mulheres estão mais participativas nas tomadas das decisões voltadas para a produção ou instalação de equipamentos sociais, como escolas e unidades de saúde para prestarem assistência à população do assentamento.

Certamente, as iniciativas dos movimentos de luta pela terra, na qual se incluem as participantes da pesquisa, compreendem a integralidade do ser humano em extensão com o ecossistema. Por isso, é essencial na discussão acerca das políticas públicas de saúde discussões sobre a agroecologia, sobre como cuidar do meio-ambiente e como produzir alimentos saudáveis, sem agrotóxicos.

\section{Considerações finais}

Concordamos com Oliveira e colaboradores (2014, p. 137), quando afirmam que "conhecer e desvelar saberes de experiência produzidos por pessoas em suas diferentes práticas sociais são tarefas inacabadas, como é o próprio ser humano". Assim, não com o intuito de concluir o texto, mas com o objetivo de compartilhar as reflexões que vieram a surgir nesse caminhar, apresentamos algumas considerações sobre a experiência de pesquisar com mulheres camponesas seus processos educativos decorrentes de suas práticas de cuidado.

O cuidado em saúde foi considerado prática social por ser ação que acontece nas relações estabelecidas entre grupos e pessoas com intencionalidade de manter ou transformar a realidade. Adotamos os processos educativos decorrentes dessa prática social como objeto de estudo dessa pesquisa. Compreender práticas sociais e processos educativos tem sido desafiador pela infinidade de possibilidades que se apresentam ao se ensinar e aprender nas relações estabelecidas entre pessoas e o mundo. Estudar práticas sociais se mostrou muito importante porque é por meio delas que as tradições são passadas, a manutenção da 
saúde acontece e a realidade se transforma.

O referencial de educação popular auxiliou em todas as etapas da pesquisa, desde a estruturação da questão de pesquisa, a compreensão dos conceitos centrais da pesquisa, o planejamento da coleta de dados, até a análise dos dados coletados. Isso porque tal referencial orienta a reconhecer o saber popular como importante elemento de transformação social. Adotamos o referencial de educação popular e saúde como proposta para um fazer saúde, porque acreditamos no diálogo entre o conhecimento técnico-científico e o conhecimento oriundo das experiências e lutas populares pela saúde, assim como sugere tal referencial.

No que se refere aos aspectos metodológicos adotados, consideramos que a Pesquisa Participante tem muito a contribuir para as pesquisas com grupos populares por auxiliar no processo de inserção no cotidiano junto a esses grupos, privilegiando o diálogo e a convivência enquanto princípios a serem adotados. Diálogo que se faz na convivência metodológica, quando há um profundo respeito por aqueles com quem pesquisamos. Nessa pesquisa, uma relação de afeto se desenvolveu entre a autora-pesquisadora e as participantes, cujos laços se estabeleceram ou se estreitaram. Tanto o referencial teórico, quanto o referencial metodológico adotado não poderia ter sido mais certeiro não somente para o objetivo da pesquisa, mas também para a escolha ética de pesquisa das autoras.

Percebemos que estar junto não necessariamente significa estar de corpo presente, mas significa estarmos atentas às manifestações da outra, às suas falas e expressões, gestos, atitudes; significa participar ativamente da tomada de decisões; partilhar e compartilhar saberes, quereres, fazeres, dúvidas e inseguranças; ter conflitos, discutir, querer se afastar também é estar junto quanto compreendemos, escutamos, falamos e também calamos quando é necessário calar. Silenciamos para dar espaço à outra, para que se possa refletir, considerar argumentos, reconsiderar atitudes, isso é estar junto. E não seria possível estar junto nessa pesquisa se não prezássemos, portanto, pela convivência dialógica.

\section{Referências}

AFONSO, M. L.; ABADE, F. L. Para reinventar as rodas: rodas de conversa em direitos humanos. Belo Horizonte: RECIMAM, 2008. Publicação Eletrônica.

ALVES, Z. M. M. B.; SILVA, M. H. G. F. D. Análise qualitativa de dados de entrevista: uma proposta. Paidéia, Ribeirão Preto, n. 2, p. 61-69, fev.-jul. 1992. doi: http://dx.doi.org/10.1590/ S0103-863X1992000200007.

ARAÚJO-OLIVEIRA, S. S. Exterioridade: o outro como critério. In: OLIVEIRA, M. W.; SOUSA, F. R. (Org.). Processos educativos em práticas sociais: pesquisas em educação. São Carlos: Edufscar, 2014. p. 47-112.

BARDIN, L. Análise de conteúdo. 5. ed. Lisboa: Edições 70, 2008. 225 p.

BRANDÃO, C. R. Pesquisa participante. 5. ed. São Paulo: Brasiliense, 1981. 211 p.

DEMO, P. Elementos metodológicos da pesquisa participante. In: BRANDÃO, C. R. Repensando a pesquisa participante. 2 ed. São Paulo: Brasiliense, 1987. p. 104-131. 
EZPELETA, J.; ROCKWELL, E. Pesquisa participante. São Paulo: Cortez, 1989. 93 p.

FIGUEIREDO, A. A. F.; QUEIROZ, T. N. A utilização de rodas de conversa como metodologia que possibilita o diálogo. In: SEMINÁRIO INTERNACIONAL FAZENDO GÊNERO, 10., 2013, Florianópolis. Anais... Disponível em <http://www.fg2013. wwc2017.eventos.dype.com.br/resources/anais/20/1373241127_arquivo

autilizacaoderodasdeconversacomometodologiaquepossibilitaodialogo.pdf $>$ Acesso em: 10 maio 2014.

FIORI, E. M. Conscientização e educação. Revista Educação e Realidade, Porto Alegre, v.11, n. 1, p. 3-10, 1986.

FREIRE, P. Pedagogia do oprimido. 45. ed. Rio de Janeiro: Paz e Terra, 2005. 256 p.

LARROSA-BONDÍA, J. Notas sobre a experiência e o saber de experiência. Rev. Bras. Educ. [online], Rio de Janeiro, n. 19, p. 20-28, jan.-abr. 2002. doi: http://dx.doi.org/10.1590/S141324782002000100003.

LE BOTERF, G. Pesquisa participante: propostas e reflexões metodológicas. In: BRANDÃO, C. R. Repensando a pesquisa participante. 2. ed. São Paulo: Brasiliense, 1987. p. 51-82.

MANZINI, E. J. Uso da entrevista em dissertações e teses produzidas em um programa de pósgraduação em educação. Revista Percurso, Maringá, v. 4, n. 2, p. 149-171, 2012. Acesso em: 13 dez. 2018. Disponível em: <http://hdl.handle.net/11449/114753>.

MÉLLO, R. P. et al. Construcionismo, práticas discursivas e possibilidades de pesquisa. Psicologia e Sociedade, Belo Horizonte, v. 19, n. 3, p. 26-32, 2007.

MINAYO, M. C. de S. O desafio do conhecimento: pesquisa qualitativa em saúde. 8. ed. São Paulo: Hucitec, 2004. 269 p.

MOURA, A. F.; LIMA, M. G. A reinvenção da roda - roda de conversa: um instrumento metodológico possível. Revista Temas em Educação, João Pessoa, v. 23, n. 1, p. 98-106, jan.-jun. 2014.

NASCIMENTO, M. A. G.; SILVA, C. N. M. Rodas de conversa e oficinas temáticas: experiências metodológicas de ensino-aprendizagem em geografia. In: ENCONTRO NACIONAL DE PRÁTICA DE ENSINO EM GEOGRAFIA, 10., 2009, Porto Alegre. Anais... Disponível em: <https://www. researchgate.net/publication/281526063_rodas_de_conversa_e_oficinas_tematicas_experiencias metodologicas_de_ensino-aprendizagem_em_geografia >. Acesso em: 18 abr. 2018.

OLIVEIRA, M. W. et al. Processos educativos em práticas sociais: reflexões teóricas e metodológicas sobre pesquisa educacional em espaços sociais. In: OLIVEIRA, M. W.; SOUSA, F. R. (Org.). Processos educativos em práticas sociais: pesquisas em educação. São Carlos: Edufscar, 2014. p. 29-46

OLIVEIRA, M. W.; MORAES, J. V. Práticas populares de saúde e a saúde da mulher. APS, Juiz de Fora, v. 13, n. 4, p. 412-420, out./dez. 2010.

OLIVEIRA, M. W.; MORAES, J. V; STOTZ, E. N. Perspectivas de diálogo entre organizações governamentais e não governamentais e instituição acadêmica: o convívio metodológico. In: 
REUNIÃO ANUAL DA ANPED, 27., 2004, Caxambu. Anais... Disponível em: < http://www.anped. org.br/reunioes/27/gt06/t0610.pdf>. Acesso em: 10 maio 2014.

OLIVEIRA, R. D.; OLIVEIRA, M. D. Pesquisa social e ação educativa: conhecer a realidade para poder transformá-la. In: BRANDÃO, C. R. Pesquisa participante. 5. ed. São Paulo: Brasiliense, 1981. p. 17-33

QUEIROZ, M. I. P. Relatos orais: do indizível ao dizível. Ciência e Cultura, São Paulo, v. 39, n. 3, p. 272-286, 1987.

RIBEIRO JÚNIOR, D. Criação audiovisual na convivência dialógica em um grupo de dança de rua como processo de educação humanizadora. 2009. 144 f. Dissertação (Mestrado em Educação) - Programa de Pós-Graduação e Educação, Universidade Federal de São Carlos, São Carlos, 2009.

STOTZ, E. N. Dicionário da educação profissional em saúde. Disponível em: < http://www.epsjv. fiocruz.br/dicionario/verbetes/parsoc.html>. Acesso em: 28 maio 2018.

VÁZQUEZ NAVARRETE, M. L. et al. Introdução às técnicas qualitativas de pesquisa aplicadas em saúde. Série Publicações Técnicas do Instituto de Medicina Integral Professor Fernando Figueira - IMIP, Recife, n. 20, p. 51-94, 2009.

Submetido em 17 de setembro de 2018.

Aprovado em 10 de outubro de 2018. 